\section{Ant Adurress}

ON

\section{THE MOIERN TREATMENT OF FRACTURES.}

Delivered at the Annual Megting of the Cardiff Medical Society on June 4th.

BY JUST LUCAS-CHAMPIONNIËRE,

HONORARY SURGEON TO THE HÔTEL-DIEU, PARIS; MEMBER OF THE FRENCH ACADEMITE DE MÉDECINE; PREBIDENT OF THE INTERNATIONAL SOCIETY OF BURGERY.

Gentlemen, - I no doubt owe the honour you have done me in asking me to deliver an address on this occasion to the fact that $I$ am an old student of the British universities. When I was a young man, soon after completing my studies in Paris I paid a visit to this island, early enough to see the surgical science of Lister at its dawn, and I am happy to-day to remember and to state that since that time I have been among those who have elways rendered just homage to the soience of your country. This is not because, like certain philosophers, I think that Science has no country; on the contrary, I believe that.we ought to be as proud of our country's men of science as of our great soldiers. But the man of science is fortunate in that he is imbued with an additional sentiment added to the love of his own country, and that is a sincere admiration and brotherly sympathy for all those who in foreign countries have enriched the science to which he himself has devoted his life.

The best way of proving sympatliy and sincere admiration for a scientific association which meets to celebrate a long and laborious past is to present to it a review of a subject to which the speaker has for many years himself given much attention. I propose, therefore, on this occasion to speak on the modern treatment of fractures, not only because I believe firmly in the efficacy of a mode of treatment which I myself introduced, but also because the profession in this country is still under the influence of the righteous emotion caused in the surgical world by the unjust accusation to which your compatriots were subjected.

That it is possible for such injustices to occur is due not merely to the existence of a feeling unfriendly to the medical profession, but also to the important changes which the method of treating fractures has recently andergone, changes not fully known to the medical world, and still more imperfectly known to the non-medical pablic. The importance and gravity of the subject will, I hope, interest you sufficiently to induce you to forgive any deficiencies in my address.

Treatment by Reduction and Splints.

The truth is that within recent times the classical treatment of fractures has been undergoing a radical change.

It is a remarkable fact that the treatment of fractures, the beginnings of which go back so far into the mists of time that we have no idea of the era when splints and treatment by immobilization were invented, has always rested upon the same data and upon the same principles ever since the first beginnings of the science of surgery.

Read any treatise on fractures, from the most ancient to the most modern, from Hippocrates to Ambroise Paré, to Dupuytren and Malgaigne and Hamilton; read all the encyclopaedias, even the titles of which I cannot enumerate-every one of them will tell you that movement is the enemy of the formation of callus, and of bony repair; that it is an obstacle to the formation of callus, so that defective consolidation, whenever it is observed, is attributed to movement having been permitted. In order to obtain the union of fractures, all practitioners have taken account of one fact alone, that a bone is a rigid lever. When it is broken the fragments must be fixed in the position of the normal bone and immobilized. To reduce and to immobilize are the only measures upon which attention is riveted.

Ambrbise. Paré, the first surgeon who boldly relied on his own personal observation, whose imagination was always alive to find out something new; often hesitates between his own imagination and the ancient traditions as to fractures; but he ends up always with remarks which impel him to greater exactness and greater violènce to ensure the reduction of fractures and their maintenance in position. Beyond this he gives information only as to the drugs which might favour the production and the union of bone. With the exception of this last point, the aims of Dupuytren, of Malgaigne, and of Hamilton are exactly the same, although, like all nineteenth century writers, being convinced that they possess much more accurate views on anatomy and physics than the older writers, they apply procedures for reduction and maintenance still more rigorously, and invent new details in the methods of reduction and in splints.

The strange thing is that they are so persuaded that they really reduce fractures, and that they favour union by immobilization, that they pay little or no heed to clinical observation. It does not occur to them to try any other means. If their results are bad, their only thought is to attribute the failure to the inadequacy of the means of reduction and immobilization which they had adopted.

Here and there in their writings on fractures it can be clearly perceived that some great observers were disturbed by facts which as it were struck them in spite of them. selves. Malgaigne had indeed seen untoward results due to muscular contraction in fractures of the lower limb, and he thought that in the inclined plane he had found a means of preventing them. Hamilton, speaking of fractures of the elbow, recommends that the fragments should be immediately mobilized at the risk of not obtaining good adjustment, because it is essential to prevent ankylosis. Velpeau recommended that in fracture of the radius the splints should never be tightly applied, for fear of causing permanent ankylosis. The doubts expressed by these surgeons show that the evil consequences of immobilization could not have been altogether unknown to them, yet not one of them was bold enough to run counter to accepted opinions; all soon returned to the employment of the most complete possible immobilization after the most violent reduction. We find the greatest surgeons devising most extravagant appliances, such as Dupuytren's splints for fracture of the radius, the action of which is utterly futile, because, from a point d'appui in itself detestable, it has to oppose the contraction of the muscles, and the cicatricial contraction at the site of the fracture; or again, that apparatus of Desault for fracture of the clavicle, which recalls the "Maiden," the torture jacket of the Middle Ages, under which the contraction of the muscles renders certain in the future the maximum possible deformity owing to overriding of the fragments of the bone.

Every one of these authors, not excluding even those who hesitated, all come back to the formula which Malgaigne very frankly placed at the head of his great treatise on fractures:

"The treatment of fractures can be summed up in two great indications : Reduce the fracture and keep it reduced until consdlidation is complete."

The nineteenth century saw the birth of a considerable number of works on fractures; all of them rely, above everything else, on physical or geometrical theories of the mechanism of fractures; if they discuss treatment at all, it is only to describe new means for the forcible reduction of fractures and their maintenance in position.

Treatment by Irremovable Appliances.

An enormous part in treatment of this kind has been played by a new invention-that of irremovable apparatus. This method of treatment is extremely valuable in certain cases; but the infatuation for these appliances bas been such that in a very large number of cases they are the cause of the very worst evils that can be produced by im. mobilization. To realize the regrettable results of this absolute immobilization upon the nutrition of the limbs we must come down to our own times. The problem presented by the treatment of fractures, which used to be "reduce, and maintain relative immobility," has now become " reduce, and enforce absolute immobility of one or several segments of the limb without regard to the duration of the immobilization."

The. Origin of Modern Treatment.

It was perhaps the very exaggeration of the evil produced by the abuse of this ingenious inverition that [2528] 
contributed to bring about an understanding of the necessity for a change in treatment. So far as I myself am concerned, it was the excess of the evil which, more than any other fact, particularly struck me. The excess of the evil opened my ejes to the inconveniences of immobility, and to the part which mobility ought to play in the repair of fractures. This observation it was which emboldened me to make mobilization a leading principle in the treatment of fractures. The success of the treatment has been due to the very numerous clinical observations which have demonstrated the truth of the principle.

But to bring about an abrupt change in treatment, and to replace a bad by a good line of treatment, it is not alone sufficient for observers to recognize the existence of the evil. Our art must advance by slow steps, and it is well to learn how a change which upsets all the oldest principles could be made, how it could even enter the mind of an observer, and how it could be adopted by the majority of surgeons accustomed to another practice, which, although it presents many disadvantages, yet has for centuries rendered services at once incontestable and nncontested. This progress in therapeutics must be brought into relation with the great scientific changes by which modern surgery has been created. The paradoxical idea of introducing movement as a part of the treatment of fractures, and its acceptance by the medical public, must in fact have owed its development and its success to some very strong reasons.

Before making known the results of my own observa. tions and experience, I long meditated upon the facts, and I can assert that I only made up my mind to publish conclusions contrary to all received ideas, and to initiate a revolution in treatment, because I was witnessing and taking a part in the transformation which surgery was undergoing.

Pasteur and Lister had so completely upset all our earlier notions that their example forbade any hesitation in submitting the best established scientific and practical theories to severe criticism. They inspired me with the courage which alone could lead to useful discoveries, and transform what it is most difficult to transform-practices resting upon most ancient customs, such as are to be described by the word " routine."

My assertions as to the remote consequences of the dis. coveries of Lister may be considered exaggerated, yet I am profoundly convinced of this indirect influence of a great piece of scientific. work, and more especially of a piece of work which brought about a radical transformation not only in scientific theory, but also in the mechanical execution of the details of the surgeon's own acts, a change which completely upset his habits in practice.

This extraordinary piece of work which upset all our habits and destroyed the whole edifice of our surgical education, produced in us such an aptitude for change that I also found it possible to accomplish another piece of destructive scientific work, which, while it has its own dangers, can alone lead to great transformations in science and in practice.

The relation of the change which I have adrocated to our older education is in fact very singular. A distin. guished American surgeon, Caldwell, of Freeport, who had assiduously followed my practice at the Beaujon Hospital, and had watched my treatment in the various types of fractures treated there, said in summing the matter up: "It is a very strange thing, after spending all one's life as a surgeon and following scrupulously the precepts of surgery, to realize that one lias been steadily deceived, and that in a practical matter so well established as the treatment of fractures one has been doing evil where one believed that one was doing good."

Is not this the very same idea that Sir William Bennett has sought to express in the introduction to his Lectures on the use of Massage and Early Passive Movements in Recent Fractures?

Indeed, it cannot but excite surprise in the mind of an intelli. gent person that the stiffness, pain, and other disadvantages which so constantly follow the treatment of fractures upon classical lines, should have been countenanced for so many years when they can, in the majority of cases, be entirely obviated by a treatment so simple as that described in the following lectures.

To break so completely with acquired habits, even when the change is the consequence of numerous positive obser. vations, is in truth a revolution, and revolutions are only made when the reasons in their favour are many and strong. The transformation wrought in our scientific mentality, giving it a degree of boldness which might seem to be temerity, undoubtedly had a leading part in influencing my course.

But the advance of surgery is always complex, and it must not be forgotten that other considerations influenced my mind, leading me to study the fundamental influence of movement on the vitality and on the regeneration of organs damaged or destroyed by injury. It is no doubt true that these considerations also have no very direct bearing but they are the consequence of the advance of science and of the contemporary progress of medicine and physiology. When the study of many of the empirical methods of massage and gymnastics was commenced in France, the study of movement was at the same time founded and developed. In this study two great French men of science were the chief leaders. Marey, by his methodical and in a certain sense mathematical study of all movements, taught us to register and reproduce them in pictures which were at once true and expressive; while Lagrange introduced medical analysis into the study of functionah and gymnastic movements by applying the physical ideas of Marey to sport and training. It is, at any rate, the fact that my acquaintance with these two men of science con. tributed to lead me to study movement from the point of view of its physiological and pathological consequences in fractures and in injuries of the joints.

Since that time a considerable number of men of science, teachers of gymnastics, masseurs, and others, have carefully studied all the scientific facts bearing on the subject, and the present position of what is calleds physio-therapy is the result of a series of quite modern investigations.

The study of movements from the educational and therapeutic points of view seems to have originated in France during the last century. The aims of the gymnastic methods of Amoros and Laisne were at first educational, but their applications in my country long remained very restricted, whereas in England and in America the love of sport gave origin to important empirical ideas with regard to movement and to training. It was, however, in Sweden and Norway especially that the study of movement from the educational point of view and the development of the art of massage were given a truly scientific character, and was controlled by men of science and doctors, while in every other country it remained the property of empirics.

We must, in fact, not fail to recognize that the share of Sweden and Norway in the evolution of massage and gymnastics has been scientific. It must not be supposed that the fundamental difference between the system of gymnastics known as Swedish and other systems lies in any actual difference in the movements. The merit of the Swedish system of gymnastics lies in the application of scientific rules and of a definite method. The cause of its success is to be found in this methodization. Various very different forms of movement are capable of giving equally successful results if they are measured and if they are performed on a regulated system. Again, it is the method or system which has rendered it possible to use this thera-peutic procedure in many very different forms of education. and treatment.

Treatment by Massage and Early Movement.

With regard to the treatment of fractures which $I$ adrocate, I will say this, that my success has been due, more than anything else, to the introduction of a strict. method of applying special forms of movement to the treatment of fractures. It is the method which has rendered possible the generalization of this therapeutic measure and its application to all forms of injury of the. skeleton and of the articulations.

It is not unprofitable thus to recall the spirit of the. method which served as a clue to guide me in working out. a therapeutic revolution, and it is in fact true that each successive step can be traced in the history of my various trials and investigations, and in the order in which my various applications of the method succeeded one another I began by lessening the degree of immobility; next I did away with it altogether; next I began to use movements. at an early stage; then I began to use them immediately after the injury; finally, I made use of massage, that is to 
say, of a method of mobilizing the muscles, the joints, and even the bony fragments. It was necessary to define the indications and the limits of this special form of movement. Thus it was that years of observation and experiment led me to establish the bold practice of methodical therapeutic mobilization.

It is a singular thing to realize that it was through my own detailed studies that I did this, and that, apart from my personal researches, nothing was published before the appearance of the description of my method. The only instance in which massage had been used for a fracture at about the time at which I developed a complete method was for fracture of the patella; it was so used by Metzger, who apologized for applying massage to a fracture, on the ground, as he said, that in this particular fracture bony union could not be obtained. The same masseur, in diseussing sprains of the ankle, stated specifically that massage should not be used if the malleolus was fractured.

At the very same period I showed, in opposition to this, that massage favoured the production of new bone, and later on the beautiful experiments of Cornil on animals proved that this result of the mobilization of the frag. ments was invariably to be observed, and in young animals was too great.

Having carefully studied all earlier observations which might have served as precedents for my method of mobilization and massage, I have satisfied myself that mone such existed.

\section{Suture of Bones.}

Since my method was devised and generalized two important means for the study and the treatment of fractures have seen the light of day; these are suture of bones and radiography.

I do not wish to decry immediate suture of fractured bones. When Sir Hector Cameron performed the first suture of the patella, when Lord Lister published his erticles on the subject, I was the first to follow their example. I believe, indeed, that I am to this day the surgeon who has performed the operation cf suture of the patella in a greater number of cases than any other in the world. I believe also that there are few surgeons more familiar than $I$ with the suture of bones in general. I consider that most valuable results can be obtained from immediate suture performed antiseptically.

But the question is, Does the suture of bones used as a general method for treating fractures in the way recommended by Arbuthnot Lane in England, Lambotte of Antwerp, Tuffier of Paris, and many other surgeons, deserve to be generalized and preferred to every other method? Without denying its conspicuous advantages, a must say that for my part I do not think so. I believe that it is a sort of continuation of the old method of ceduction and fixation of the fragments. It would seem, indeed, to be the ideal of reduction followed by smmobilization, and has in fact been held to be the most perfect realization of the old precept as to the treatment of fractures. It is certain also that the more the method of mobilization is developed the fewer will be the occasions on which immediate suture will be performed. If, as I have shown, a small amount of movement assists the process of repair at the site of fracture, it is quite evident that suture cannot be the ideal mode of treatment, for it ought, if properly performed, to do away with all movement of the fragments. I can at once give a practical example of this; suture of the olecranon is undoubtedly the simplest of all operations of the kind. I have done it for old fractures inadequately treated by other surgeons. I have never had occasion to do it for recent fractures properly treated by my method, because perfect recovery is obtained within a fortnight. without operation.

\section{RADIOGRAPHY.}

Since I began the treatment of fractures by movement, light has been thrown on the study and the treatment of fractures from another new and important source; this is the application of radiography to the examination and to the treatment of fractures.

Although I am the author of an essay on the errors of radiography, I appreciate the importance of radiography in regard to fractures; but I hold that on the one hand radiography cannot dispense us from the study of the symptoms of fractures, and on the other that it cannot warrant an untrained person replacing a doctor in making a diagnosis and in treating fractures.

Radiography gives us only a picture of the projection of a bone, and is subject, therefore, to many more drawbacks than ordinary photography by reflection. Consequently it is necessary very critically to examine images which for a multitude of reasons may give misleading pictures of the site of the fracture. It is necessary to learn how to appreciate the real value of a radiogram; only after much experience can one become a good judge of radiograms of fractures, even when these radiograms have been well taken. A radiogram which is badly taken may give rise to a multitude of errors of representation which ought to be known, and which produce many mistaken ideas in the mind of the non-medical public.

Subject to these two reservations, radiography is a marrellous aid in the diagnosis and in the treatment of fractures. From this time forth the surgeon ought never to fail to use it whenever it is possible to do so. Nevertheless the value of the help it can give varies very much. In the immense majority of cases there is very little chance that abstention from resort to radiography will prevent us from arriving at o. correct diagnosis and the institution of proper treatment; it is essentially necessary in rare cases only. In the majority of instances it is only an additional security, giving a useful assurance to us, and to the friends of the injured person an interesting demonstration, and a document for future use.

Radiography has afforded me very special help in all that concerns my own standpoint with regard to the treatment of fractures. I have long maintained that surgeons who supposed that in reducing fractures they adjusted the bony fragments end to end and restored them to their normal position were deceiving themselves, and that in spite of faulty position, in spite of a certain degree of persistent overriding, the function of the limb again became perfect. The object which we must have in view in treatment, then, must not be this ideal juxtaposition.

Radiography has, in fact, surprised surgeons very much by showing them fractures well and soundly cured, with excellent functional results, but with considerable bony displacement. Very often, indeed, surgeons not fally acquainted with these matters, and still more patients, on examining such radiograms have been led to believe that errors have been made, even when the function of the limb is as perfect as the nature of the injury renders possible. What we are thus taught will prove very valuable in establishing a modern treatment of fractures.

The Modern Method.

After this very short summary of the history of the treatment of fractures down to the present day, let me next explain my conception of what this treatment by movement is, and state the new facts observed by me which give a revolutionary character to my method.

A certain amount of movement between the fragments ensures the best bony repair; this is the corner-stone on which my method is based. Every movement which is not injurious by reason of its amplitude favours repair; but it must be understood that the movement must be measured-dosed, so to say.

The movement which is necessary for the repair of the bones is not less necessary to the vitality of all the constituent parts of the limb, and particularly for all the organs of motion-joints, muscles, ligaments, and tendons.

The relation which the movements have to pain experienced by the patient are not such as is commonly helieved ; certain kinds of movement help to relieve the pain. Immobilization, whi sh seems to relieve, only gives momentary relief, for it prepares the way for other pains in the future. Mobilization, gently performed as early as possible after the injury to the bones, is the method which best promotes disappearance of the pain.

Massage affords the best form of movement. By simple mobilization, by massage, and even by his own examination, the surgeon ought never to cause pain, for the pain so caused leads to fresh pain and produces complications.

The reduction of a fracture is only a relative necessity ; it should be resorted to only in certain deformations of the axis of the bone which are incompatible with the function of the limb-lower third of the leg, shaft of the humerus. In a large number of cases the manceurre of reduction is useless; it is useless in all fractures of the radius with 
impaction and moderate deformity, in most fractures of the upper extremity of the humerus, and in the great majority of fractures- of the neck of the femur. In all fractures in which the displacement is due to muscular contraction any attempt at reduction is useless, as in fracture of the clavicle, of the olecranon, and many fractures of the malleoli. After massage the fracture is either spontaneously reduced, as in the case of the olecranon, or is very easy to maintain reduced, as in the case of the clavicle and malleolus. Those conditions which favour the vitality of the limb ara all more important than those which produce immobilization of the fragments. The fact that shortening has not the injurious influence on repair which it is said to have should not be lost sight of when considering dísplacement. A moderate degree of shortening which does not change the static position of a limb is farourable to repair. The muscles surrounding a shortened lever act more rapidly and better than upon a lever on which they are stretched. A certain amount of shortening ought not to be interfered with, as it is favourable to the repair of a broken bone.

Massage has so great an effect in stimulating bony secretion at the site of fracture that in children, in whom the activity of the production of bone is great, massage ought not to be applied, save with great moderation, for fear of provoking excessive osseous secretion-in fact, a tumour. In their case simple mobilization is often sufficient.

Mobilization from the beginning, within the first twentysfour or forty.eight hours, is of capital importance, and: at this stage movements of very small amplitude are sufficient; passive or -induced movements are the best at the beginning. Active or spontaneous movements ought to be measured and directed by the surgeon; to allow the patient to follow his own fancy with regard to active movements is dangerous - all the more dangerous because with my method the pain caused by movement disappears from the beginning, and therefore does not limit the untimely action of voluntary movement. The pain experienced and the degree of sensitiveness of the callus are the best guides in directing and in permitting movement by the patient.

The secondary treatment of fractures and their supervision ought to be prolonged. Functional use of a fractured limb is the condition most favourable to its regaining actioe power. Even during this secondary period everything likely to irritate the region of the callus ought to be avoided. It is useless to cause pain by movements exaggerated in amplitude or by resort to forcible manipulation.

While before my investigations the surgeon contented himself, after having reduced a fracture, by awaiting cure, the modern surgeon should play a much more active, much more personal, and much less simple part. He ought not only to diagnose the fracture but ought to make its exact nature visible by a radiographic picture, and then take action to obtain not only solidity of the limb, but also to restore its suppleness, its regularity of action, and its power. He must not merely await the solidification of the skeleton. Moreover, his treatment must vary a great deal according to

\section{The age,}

The variety in the site of the fracture,

The kind of fracture of the limb,

The general or local health of the patient,

His occupation,

and aocording also to the circumstances under which he is called upon to, act, for if he cannot ensure proper personal supervision of mobilization, massage, and the supervision of the morements, it may happen that he will be compelled to replace an excellent method of mobilization by a moderately good method of suture, or absolute immobilization.

The surgeon needs a great deal of experience to conduct the treatment of a frocture in the best way, and I cannot help asking with some anxiety how a non-medical tribunal is to form a judgement on questions so complex, should the patient and his medical attendants cease to be in accord.

The situation is complicated. Well-to-do people bring actions against surgeons because they continue to experience pain or stiffness after a fracture; workmen reproach the surgeon because he cures them too well, inasmuch as by causing the disappearance of all secondary pain, accidents are not followed by the permanent infirmity for which they hoped.

The whole history of the surgery of fractures cannot be related in an address which is already too long, but I shall have succeeded in my purpose if I have made plain to you to how great an extent the duty of the surgeon has become, difficult indeed, but effective in this matter of fractures, Instead of waiting for the injured person to cure himself, we can cure him and quickly restore to him the use of his limb.

It is a laborious task, more difficult than the banal application of irremovable appliances; it is still insufficiently understood by the profession, and altogether unknown to the public. But I am proud to think that in your country it has met so favourable a reception that you have been willing to listen to the exposition of the subject which I have to-day offered to you as a tribute of fraternal homage.

\section{An Andress \\ oN THE}

\section{PRODROMAS OF MIGRAINE.}

Delivered before the Westminster Division of thB British Medical association.

BY

Sir WILLIAM R. GOWERS, M.D.Lond., F.R.S.

Gentlemen,-I have chosen a subject for your consideration with which every. practitioner is familiar from the accounts of his patients, and a good many are also well acquainted from personal suffering-the curious sensory symptoms that constitute the premonition of attacks of migraine, using the term as equivalent to paroxysmal headache, The symptoms occur before every form of such headaches, those which are bilateral, as well as those that may be strictly termed " hemicrania," but both are common without premonition.

The knowledge we have of these peculiar symptoms, the prodromas of migraine, is very small; compared with their frequency, their detailed features, and the facility which frequent recurrence affords for their collection. It is easy to explain the paucity of facts. Observation under conditions of distress is not easy. especially when minute precision is needed. A graphic presentation of visual sensations, such as that which was afforded by Dr. Airey, can only be recorded from memory, because vision is too much interfered with by the subjective disturbance at the time. A knowledge of, or at least some acquaintance with, the physiology of sensation is necessary for the full use of the opportunities which are met with, especially by personal observation. It is the hope that $I$ may excite some to careful record, that makes me choose this subject for consideration, and describe some cases which illustrate the leading features of these strange mani festations. I will, however, endeavour to avoid repeating those that I have given in the Bowman Lecture on Subjective Sensations of Sound, and in the lecture on migraine in. The Borderland of Epilepsy. I do not pro. pose to discuss their nature, although it is difficult to avoid alluding to the hypotheses that have been brought forward.

The prodromas are a functional disturbance in the sensory region, and so is the headache which succeeds. But the headache may be termed a coarse disturbance consisting of pain, often most intense, and sometimes with some secondary effects of its severity. On the other hand, it may be slight and of short duration, and it may be even absent, the prodroma oceurring alone. These premonitory symptoms, although sensory, do not include pain. They are restricted in range. The sense of sight is often involved, sometimes by loss, partial or general, sometimes by an elaborate display of its higher crude functions in light, colour and apparent motion. Other special senses do not participate, except the sense of touch. Neither smell, taste, nor hearing seems to be involved, although there is rarely a slight degree of vertigo, the precise nature of which is not clear. The involvement of cutaneous sensibility seems to be of touch, and is a frequent and 